\title{
UMA ANÁLISE CULTURAL DA GEOFAGIA HAI- TIANA: A DESCONSTRUÇÃO DO "BISCOITO DE BARRO” DA IMPRENSA BRASILEIRA
}

\author{
JHON KELLY MONACÉ \\ UNIVERSIDADE FEDERAL DO TOCANTINS \\ PALMAS, TOCANTINS, BRASIL \\ JHON-KELLY.MONACE@MAIL.UFT.EDU.BR@GMAIL.COM \\ TEMIS GOMES PARENTE \\ UNIVERSIDADE FEDERAL DO TOCANTINS \\ PALMAS, TOCANTINS, BRASIL \\ TEMIS@UFT.EDU.BR \\ ANTONIO JOSÉ PEDROSO NETO \\ UNIVERSIDADE FEDERAL DO TOCANTINS \\ PALMAS, TOCANTINS, BRASIL \\ AJPEDROSONETO@UOL.COM.BR
}




\section{UMA ANÁLISE CULTURAL DA GEOFAGIA HAITIANA: A DESCONS- TRUÇÃO DO “BISCOITO DE BARRO" DA IMPRENSA BRASILEIRA}

Resumo: O artigo apresenta duas representações da geofagia no Haiti. Uma que a imprensa criou e divulgou; o "biscoito de barro" para saciar a fome. Assim, ela se referiu ao tè e ao seu consumo, de modo equivocado e sensacionalista. Em contraponto, o artigo apresenta análises de entrevistas com geófagos locais. Elas revelaram que os comedores de tè apreciam seu gosto, têm crenças em suas virtudes medicinais e aprendem este hábito alimentar do mesmo modo que outros hábitos.

Palavras-chave: Haiti; Geofagia; Biscoito de barro; Tè; Imprensa.

\section{UNA ANÁLISIS CULTURAL DE LA GEOFAGIA HAITIANA; LA DES- CONSTRUCCIÓN DEL “BISCOITO DE BARRO” DE LA PRENSA BRASI- LEÑA.}

Resumen: El artículo presenta dos representaciones de la geofagia en Haití. Una que la prensa creó y divulgó; la "galleta de barro" para saciar el hambre. Así, ella se refirió al tè y su consumo de modo equivocado y sensacionalista. En contraposición, el artículo presenta análisis de entrevistas con geófagos locales. Ellas revelaron que los comedores de tè aprecian su gusto, tienen creencias en sus virtudes medicinales y aprenden este hábito alimentario del mismo modo que otros hábitos.

Palabras clave: Haití; Geofagia; Galleta de barro; Tè; Prensa.

\section{A CULTURAL ANALYSIS OF THE HAITIAN GEOPHAGY; THE DECONS- TRUCTION OF THE “BISCOITO DE BARRO" OF THE BRAZILIAN PRESS.}

Abstract: The article presents two representations of geophagy in Haiti. First, there is what the press has created and released; the "clay biscuit" to quench hunger. Thus, the press referred to tè and its consumption in a wrong and sensational way. In contrast, the article presents analyzes of interviews with local geophagous who revealed that consumers appreciate the taste of tè and have beliefs in its medicinal virtues and learn this eating habit in the same way as other habits.

Keywords: Haiti; Geophagy; Clay biscuit; Tè; Press. 


\section{INTRODUÇÃO}

A geofagia é a prática dos indivíduos de ingerirem solo ou argila, ou, como a maior parte dos textos registra; comer terra. As práticas de geofagia estão inseridas em culturas específicas e variam de uma sociedade para outra. É um comportamento complexo com várias causas e origens; crenças religiosas e espirituais, rituais e cerimônias, necessidades e práticas medicinais e nutricionais, etc. (COLLIGNON, 1992; HUNTER, KLEINE, 1984; KACHA$\mathrm{NI}$, CORDAS, 2009; PESSOA, 2005). Ela é uma prática humana e animal que atrai a atenção de pesquisadores das ciências sociais e das ciências da saúde (LIEWIG, RAUTUREAU, GOMES, 2012).

A prática da geofagia remonta a um longo período na história da humanidade e deixou vestígios na América Latina, nas culturas africanas e nos Estados Unidos da América (HUNTER, KLEINE, 1984; KACHANI, CORDÁS, 2009). Nos Estados Unidos da América, e em outros países desenvolvidos, é analisada, principalmente pelos psiquiatras, como um distúrbio psíquico (PESSOA, 2005). Mas a geofagia das análises e visões dos etnógrafos difere da geofagia dos estudos médicos, uma vez que aqueles consideram que as pessoas não comem o solo ou a argila da mesma forma (CHAPART, 1926 apud COLLIGNON, 1992). Essa forma de ver a geofagia se refere à esfera cultural da alimentação humana. É assim que alguns pesquisadores que estudam as culturas africanas consideram a geofagia, a partir de uma abordagem sociológica (COLLIGNON, 1992).

O Haiti' é uma das sociedades contemporâneas que mantém a prática da geofagia por meio do tè. Não há pesquisas científicas sobre a geofagia haitiana e, particularmente, sobre o tè. Por isso, iniciamos o tratamento do assunto propondo uma apresentação do tè baseada em observações e entrevistas com geófagos.

O tè é uma massa de argila que se torna comestível quando é misturada com água, sal, manteiga e azeite. Depois é moldada - geralmente ganha uma forma redonda -, secada ao sol e consumida ou comercializada. É feita pelo próprio consumidor ou em uma fábrica tradicional que produz para o

\footnotetext{
1 A República do Haiti, com suas ilhas adjacentes - Gonâve, Ile de la Tortue, o Cayemites, Grosse Caye, Navase e as outras ilhas do mar territorial - tem uma área de $27.750 \mathrm{~km} 2$. O país ocupa o terço ocidental da ilha do Haiti, do arquipélago das Grandes Antilhas, que compartilha com a República Dominicana. E, administrativamente, está dividido em dez departamentos geográficos. Sua população total foi estimada em 10.911.819 habitantes em 2015 (INSTITUT HAïTIEN DE STATISTIQUE ET D’INFORMATIQUE, 2015).
} 
mercado local, nacional ou para fora das fronteiras haitianas. A argila no idioma crioulo - kreyòl - haitiano é ajil. Ela é extraída de uma mina do Departamento do Centro. Quando a argila não é misturada a outros ingredientes, é chamada de ajil. Quando é misturada com água, azeite, manteiga e sal se torna tè. Tè em outro contexto social da linguagem haitiana quer dizer: lote, terra, fazenda.

Na literatura específica, não há registros sobre o início da prática da geofagia no Haiti (COLLIGNON, 1992; HUNTER, KLEINE, 1984; KACHANI, CORDAS, 2009; PESSOA, 2005). De qualquer forma, o consumo do tè nas práticas culinárias ou alimentares dos geófagos haitianos remonta a inúmeras gerações. Geralmente, são as mulheres e as crianças de ambos sexos que comem. Ao crescerem, os meninos, gradualmente, tendem a abandonar a prática, enquanto as meninas tendem a manter. $O$ tè não é consumido em rituais, mas sim no dia a dia da maioria dos comedores. Como o consumo do caolin - um minério, conforme a química e a mineralogia - pelas imigrantes africanas de Paris e suas conterrâneas da África do Oeste (PESSOA, 2005) e como tantos outros minerais consumidos por geófagos (HUNTER, KLEINE, 1984; KACHANI, CORDAS, 2009; PESSOA, 2005), o consumo do ajil como tè é uma prática cultural, é constitutivo da dieta de alguns segmentos da sociedade haitiana. Dito de outro modo, é parte do menu de comidas regularmente preparadas e consumidas.

Contudo, a geofagia do Haiti foi objeto de rumores sem precedentes na comunidade internacional, durante os motins da fome de 2008 e os anos após o terremoto de janeiro de 2010. Os motins da fome ${ }^{2}$ no Haiti foram eventos que perturbaram o país e mostraram que a segurança alimentar era difícil de ser garantida, tanto pelas famílias haitianas pobres quanto pelos governantes do país. Eles causaram uma onda de violência seguida por atos

2 Por motins da fome queremos dizer, as inúmeras lutas e resistência por parte da população pobre contra o aumento do preço de alimentos ou inacessibilidade aos alimentos. Há várias pesquisas históricas sobre esse fenómeno na França e na Inglaterra do século XVIII (OLIVEIRA, 2005; THOMPSON, 1987). Mas, os motins mais recentes que marcaram a historia mundial foram os de 2008 que afetaram o Haiti. Janin explicou que esses eventos ocorreram em diversos países do mundo em 2008 e serviram para revelar a vulnerabilidade da economia de mercado, no nível internacional e nacional. Também mostraram que os países que enfrentavam déficit alimentar não podiam resistir ao problema, sozinhos. Foram apoiados por países agroexportadores por meio de políticas de ajuda alimentar. Desde então, a questão da ajuda alimentar se mostrou uma dimensão geopolítica inegável (JANIN, 2009). 
de vandalismo e pilhagem de lojas e casas das grandes cidades do país, a procura de alimentos.

Neste momento, os repórteres das TVs, rádios e jornais internacionais presentes voltaram suas atenções de modo especial para país; observaram e relataram atentamente os motins da fome e a geofagia haitiana. Foi nesse momento que classificaram o tè como "biscoito de barro" ou "bolacha de barro". Além disso, divulgaram informações que os Haitianos faziam "biscoito de barro" como um novo alimento para saciar a fome e como uma expressão da pobreza haitiana (ETWAREEA, 2008; CARROLL, 2008; TERRA, 2008; PORTO, 2010; GARBIN, 2017; BERGAMO, 2008; LACEY, 2008; ASSOCIATED PRESS, 2008). Quer dizer, ignoraram uma prática cultural, um hábito da dieta alimentar e a apresentaram de modo sensacionalista - "barro" -, como expressão de pobreza - vale dizer, do mesmo modo que ignoraram a grande mobilização dos haitianos para se ajudarem após o terremoto de 2010, mas enfatizaram cenas bem mais raras de violência entre eles (THOMAZ, 2010).

Enfim, com os motins, a fome no Haiti entrou nas agendas midiáticas e políticas, nacionais e internacionais e o tè foi apresentado como "biscoito de barro". Posteriormente, no momento do terremoto, a fome no Haiti retornou às agendas midiáticas (AGÊNCIA DE NOTíCIAS DE PORTUGAL, 2010; CÁSSIO, 2014; VIVAR, 2016). E, novamente, a pratica de comer tè voltou a ser apresentada como prática de comer "biscoito de barro".

Dentre a imprensa internacional que abordou a geofagia desta perspectiva, estava a brasileira. Ela publicou muitos artigos, tanto em 2008, momento dos motins de fome, quanto em 2010, momento do terremoto. Ou seja, em alguma medida, a geofagia haitiana foi tratada de forma significativa nos jornais brasileiros; impressos, on-line, blogs, televisão - reportagens na Rede Globo como no Domingão do Faustão - etc.

As informações da imprensa brasileira, em grande medida, foram muito difundidas entre os brasileiros, a ponto de que brasileiros que desconhecem o Haiti acreditarem que o "biscoito de barro" é alimento básico da refeição haitiana. Sendo assim, nos deparamos com um problema: de um lado, a existência de uma prática cultural, tradicional, histórica e com sentido para os seus praticantes, como registra a literatura para casos semelhantes (COLLIGNON, 1992; HUNTER, KLEINE, 1984; KACHANI, CORDAS, 2009; PESSOA, 2005); e, de outro lado, um relato difundido que ignora tudo isso e Ihe atribui nome e significados pejorativos. Como isso foi possível? Há uma 
literatura específica que registra os constrangimentos que pesam sobre a imprensa atualmente e que a leva a tratar os fenômenos sociais de modo superficial, rápido e com imagens, frases e relatos sensacionalistas, chocantes, chamativos para manter ou aumentar a audiência (BOURDIEU, 1997; CHAMPAGNE, 1995, 1998; SEDEL, 2013). Com base nela, nossa hipótese é simples: a imprensa simplesmente ignorou o sentido de prática cultural, o tè em um contexto sociocultural, e acentuou os traços sensacionalistas, chocantes, impressionantes possíveis dessa prática, como a ideia de comer barro diante da fome.

Em síntese, os repórteres fizeram uma observação superficial do fenômeno. Neste artigo, analisamos a imagem da geofagia dos haitianos, em grande medida, construída e divulgada para os brasileiros pelos veículos de comunicação, e algumas repercussões. Em contraposição, analisamos como os geófagos haitianos representam e praticam a ingestão do tè, ou seja, analisamos uma prática cultural relatada por seus praticantes no seu contexto sociocultural.

A seguir, primeiro, apresentamos minimamente os contextos em que a imprensa brasileira interpretou e nomeou a geofagia haitiana; dos motins da fome e do terremoto. Nesses contextos, a imprensa inventou e difundiu o nome "biscoito de barro" e seus significados correlatos sobre a prática, as pessoas e o país.

Em seguida, apresentamos as representações autóctones sobre o tè. Utilizamos dados de entrevistas com pessoas que praticam a geofagia em Cité Soleil, vizinha da capital do Haiti, Porto-Príncipe. Cité Soleil é um município com 265.072 habitantes (INSTITUT HAÏTIEN DE STATISTIQUES ET D'INFORMATIQUE, 2015) conhecido pela imprensa, de modo geral, por conta da sua miséria e da geofagia. O objetivo das entrevistas foi identificar os significados da prática cultural para os haitianos; mais precisamente, para os haitianos de um dos lugares mais observados pela imprensa internacional.

\section{A IMPRENSA BRASILEIRA E A INVENÇÃO DO “BISCOITO DE BAR- RO"}

Pelo menos em dois momentos a imprensa mundial e a do Brasil voltaram seus holofotes para o Haiti e divulgaram uma prática alimentar cultural como uma resposta dos haitianos à fome; em 2008 e 2010.

Isso começou em abril de 2008 , com os tumultos contra o aumento do custo de vida e, particularmente, dos alimentos no Haiti. Seguindo a imprensa 
internacional (ASSOCIATED PRESS, 2008; BERGAMO, 2008; CARROLL, 2008; ETWAREEA, 2008; GARBIN, 2017; LACEY, 2008; PORTO, 2010; TERRA, 2008) em linhas gerais, o aumento brusco e elevado do preço dos alimentos e a agricultura em crise foram as principais razões que provocaram os motins da fome, particularmente em Porto-Príncipe. Os tumultos foram iniciados por jovens do Departamento do Sul do país, particularmente da cidade Les Cayes. Foi uma revolta contra um governo considerado inativo que levou a população a sair às ruas (BRACCIANO, CLAUDET, 2008). Como resultado, em 12 de abril de 2008, o primeiro-ministro Jacques Edouard Alexis foi obrigado a renunciar, após de uma moção de censura que foi aprovada pelo Senado da República (LE FIGARO, 2008).

Neste contexto, no momento da crise alimentar, o Programa Alimentar Mundial buscou ajuda para o Haiti (ALTERPRESSE, 2008). E, nestas circunstâncias, a imprensa brasileira explorou a questão da fome no país. Então, ela descobriu e observou a prática da geofagia e a relacionou com a questão da miséria existente; observou o tè e o chamou de "biscoito de barro" e símbolo da miséria haitiana.

A imprensa brasileira esteve presente em 2008, quando os distúrbios relacionados à crise alimentar explodiram em Porto-Príncipe. Na ocasião, ela apresentou cenas de fome no Haiti. Em 2008, havia vários artigos da pequena e da grande imprensa brasileira sobre a fome no Haiti. Em abril, a Folha de São Paulo, reproduziu, sem reservas, um artigo do New York Times mencionado a questão do "biscoito de barro", nestes termos (LACEY, 2008):

No Haiti, onde $75 \%$ da população ganha menos de US\$ 2 ao dia e $20 \%$ das crianças sofrem de subnutrição crônica, o único negócio que floresce nessa era sombria é a venda de bolinhos feitos de barro, óleo e açúcar, tipicamente consumidos apenas pelos mais miseráveis. "Eles acalmam o estômago".

A imprensa, algumas vezes, relatou informações dos representantes do governo brasileiro no Haiti. Por exemplo, Bergamo (2008), na Folha de São Paulo, divulgou assim as palavras de Paulo Vannuchi:

Recém-chegado do Haiti, Paulo Vannuchi, ministro da Secretaria dos Direitos Humanos de Lula, trouxe na mala bolachas feitas com sal, pimenta e argila consumidas no país. Elas disfarçam a fome porque pesam no estômago, diz ele. 
O Portal Terra (TERRA, 2008) informou que a "lama" se tornou alimento no Haiti porque os haitianos não encontravam mais nada para comer. Informou ainda que eles inventaram este novo alimento, sem suporte nutricional, porque não tinham meios econômicos suficientes para comprar outros alimentos.

Repercutindo outro jornalista, o blogueiro e jornalista Gilberto Lima, Lima (2009), se refere a uma matéria jornalística do Jornal Vale do Paraíba para escrever seu próprio artigo que abordou o Haiti:

O símbolo da miséria no Haiti é um biscoito feito de barro, água e manteiga. Batizado de "Té", a receita serve para tapear a fome. Mulheres desesperadas coletam restos de construção e misturam com água e manteiga em tinas de plástico e metal velhas e sujas. Quando não há manteiga, elas usam apenas água. Raras vezes põem sal, produto de luxo. A massa encardida, da cor de argila, é espalhada em tablados de madeira ou metal e ganha a forma de biscoitos, parecidos com pequenas panquecas. As mulheres usam colheres para espalhar centenas desses biscoitos pelo chão para que sequem ao sol. Por causa da água, eles incham e depois endurecem.

O autor afirma que as mulheres estavam recolhendo restos de materiais de construção - cimento, areia, etc. - e, em seguida, adicionando sal e manteiga. Além disso, apresentou o sal como um produto de luxo no país, ignorando que ele está localizado no meio do Mar do Caribe e o sal é um dos produtos mais baratos da ilha. Entretanto, nem isso impediu que uma interpretação precária fosse divulgada. Sua matéria jornalística limitada, mal informada e não checada, ganhou adeptos entre os desavisados, a ponto de ser usada como informação com cores de verdade em artigo acadêmico, como em Tisatto (2016).

Enfim, em alguma medida, a interpretação da geofagia haitiana, feita pela imprensa, se espalhou gradualmente, e não foram esquecidas. As interpretações do tè com um apelo sensacionalista, "biscoito de barro", foram reavivadas em 2010, na ocasião do terremoto, e continuam presente até os dias atuais no imaginário dos brasileiros.

Em 12 de janeiro de 2010, o Haiti foi atingido por um grande desastre natural; um terremoto ${ }^{3}$ de magnitude 7,3 na escala de Richter. Considerando

3 Diferentes regiões e populações foram diretamente afetadas pelo terremoto, principalmente vinte cidades do departamento Oeste e dez do departamento Sudeste. O impacto 
a imensidão dos danos, a comunidade internacional se mobilizou para ajudar o país. A solidariedade internacional se manifestou por meio de um amplo espectro de equipamentos de emergência, incluindo resgate, assistência médica e ajuda alimentar aos sobreviventes - ainda que haja controvérsias em relação a isso (THOMAZ, 2010).

A comunidade internacional esteve presente também por meio de sua imprensa, que divulgou informações que terminaram atraindo mais atenção de todo o mundo. Portanto, ela realizou, em primeiro lugar, interessantes artigos sobre o Haiti. Artigos que marcaram os programas dos grandes meios de comunicação da França - Le Monde, Le Figaro, Libération, TF1 -, do Canadá - Radio Canada -, dos Estados Unidos da América - CNN, New York Times, Miami Herald - e do Brasil - O Globo, Jornal do Brasil, Folha de São Paulo, O Estado de São Paulo. Reportagens e outras matérias midiáticas foram realizadas pelos maiores canais de TV, permitindo que o mundo visse a realidade do Haiti pós-terremoto. Na verdade, o desastre significou muito trabalho de grande audiência para os repórteres, apresentadores, cinegrafistas, fotógrafos e editores da imprensa internacional. Como resultado, as emissões da grande imprensa internacional passaram horas de programação sobre o Haiti.

Em decorrência do terremoto, havia realmente a necessidade de ajuda alimentar para evitar a fome e garantir a sobrevivência do segmento da população mais afetado. Por um lado, o trabalho da imprensa contribuiu para mobilizar ajuda. Por outro lado, diante do mesmo evento, a imprensa reavivou antigas formas próprias de representação do tè e ignorou as formas culturais históricas e autóctones: divulgou que os haitianos faziam "biscoito de barro" para saciar a fome, ignorando que o tè um alimento, dentre outros, das práticas culinárias tradicionais da cultura haitiana. Em consequência, a questão da geofagia haitiana, novamente de modo equivocado, ressurgiu nas notícias internacionais, inclusive na brasileira.

A Associação São Francisco, uma ONG católica brasileira, criou uma padaria no Haiti. Frei de Jaci, um dos líderes da associação, explicou que a padaria foi inaugurada para resolver o problema das crianças que comem "biscoito de barro" e para lutar contra a fome no país (LAREZO, 2013). Quatro anos depois, a Revista Globo Rural publicou um artigo sobre a Associação

foi particularmente grave na região metropolitana constituída por Port-au-Prince, Léogâne, Grand-Goave, Petit-Goave e Jacmel. 
São Francisco e o "biscoito de barro" foi mencionado (AGÊNCIA BRASIL, 2017). Nesse artigo, o jornal relatou as palavras do Frei Gabriel Alves:

\begin{abstract}
A missão no Haiti também distribui diariamente cerca de dois mil pães, enriquecidos com uma multimistura que ajuda a combater a desnutrição. "O pão substitui o Té, um biscoito feito de barro que os haitianos usavam para enganar a fome", lembra um dos responsáveis pela Missão no Haiti, Frei Gabriel Alves.
\end{abstract}

Conforme Gabriel Alves, é a falta de pão no mercado haitiano que leva as crianças a comerem o tè. Desavisado, ele também ignora que esse alimento é constitutivo da cultura haitiana. Além disso, de fato, há abundância de padarias no Haiti e um pão é mais barato do que um Tè; um pão custa 5 Gourdes ( $(5,00)$ e um tè 10 Gourdes $(G 10,00)$ - o equivalente a $R \$ 0,28$ e $\mathrm{R} \$ 0,56$ reais, respectivamente. $O$ tè tem uma forma pequena; geralmente, redondo com cerca de dez centímetros de diâmetro e um centímetro e meio de espessura. Já o pão haitiano é como o pão francês brasileiro, ou seja, bem maior. E é mais barato do que o tè. Ainda assim, os haitianos seguem comendo tè, uma vez que se trata de uma prática alimentar com sentido social. Enfim, até mesmo um religioso ignorou este aspecto da prática da geofagia haitiana, como a imprensa brasileira.

Mais recentemente, em setembro de 2017, Luciana Garbin, enviada especial do jornal O Estado de São Paulo a Porto-Príncipe, escreveu um artigo explicando que a "bolacha de barro" é usada por parte da população para matar a fome. Segundo a reportagem, desde a Missão das Nações Unidas para Estabilização do Haiti, em 2004, o biscoito adquiriu algumas utilidades; saciar a fome dos consumidores e servir de atividade econômica para produtores e vendedores (GARBIN, 2017). Ou seja, mesmo a grande imprensa brasileira - O Estado de São Paulo em 2017 - reavivou seus antigos clichês - o tè como "símbolo da miséria do Haiti" - e acrescentou novas desinformações, de ordem utilitária; o tè permanece porque garante renda de muitos haitianos. E a imprensa regional não deixou de repercutir, dias depois. Ainda em setembro de 2017, o Diário de Pernambuco explicou que adultos e crianças continuam comendo os "biscoitos de barro" e que eles continuam sendo um símbolo da miséria (DIÁRIO DE PERNAMBUCO, 2017). Enfim, certamente, o tè, na produção e no consumo, gera renda para muitos haitianos. Mais isso antecede os motins da fome e o terremoto. Ele não entra no circuito das atividades econômicas porque é o símbolo da miséria, 
mas entrou nesse circuito porque, historicamente, há geófagos inseridos em uma cultura que o consomem por razões de sentido social.

Em conclusão, no Brasil ainda é recorrente a imprensa divulgar uma representação, um senso comum sensacionalista, de que os haitianos comem "biscoito de barro" para saciar a fome. No entanto, trata-se de um alimento articulado às normas culturais e sociais que o incluem na dieta alimentar, como veremos.

\section{A DESCONSTRUÇÃO DO “BISCOITO DE BARRO” DA IMPRENSA PELOS GEÓFAGOS HAITIANOS}

Como os geófagos pensam o tè? Como comem? Quais são os sentidos que dão a ele? Para responder essas questões, realizamos vinte entrevistas com o objetivo de identificar os significados do tè para haitianos geófagos. Foram entrevistados quatro homens e dezesseis mulheres, com idade de 20 a 34 anos, nos dias 20 e 21 de julho de 2017, em Cité Soleil. Fundamentalmente, perguntamos às pessoas, em idioma crioulo: "eske w manje tè?" (você come o tè?); "poukisa w manje tè?" (por que você come o tè?); "eske w manje tè pou konbat grangou?” (você come o tè para saciar a fome?).

Obtivemos vários tipos de respostas e as classificamos em algumas categorias, construídas a partir de uma leitura geral de todas elas. Eis as categorias: gosto e sabor; gravidez; virtudes medicinais; influências de outros geófagos; contra a fome; e outras razões. Então, observamos novamente cada uma das entrevistas e contamos cada vez que as razões apareceram, ou seja, classificamos as razões em uma das categorias. Algumas entrevistas apresentaram mais de uma razão.

Fizemos dois tipos de análise, ou seja, de contagem de frequência. Uma análise da frequência da primeira razão mobilizada em cada entrevista. Assim, apresentamos uma hierarquia das razões principais, no conjunto das entrevistas. E uma análise da frequência e da ordem de todas as razões apresentadas em cada entrevista. Deste modo, apresentamos uma hierarquia de frequência das razões no conjunto das entrevistas: classificamos como importantíssima a razão apresentada em primeiro lugar em cada entrevista; como muito importante a apresentada em segundo lugar; como importante a apresentada em terceiro lugar; e como menos importante a apresentada em quarto lugar.

Conforme a primeira análise, obtivemos a seguinte hierarquia de motivos 
principais: gosto e sabor foi relatada sete vezes; gravidez, seis vezes; virtudes medicinais, três vezes; influências de outros geófagos, duas vezes; e outras razões, duas vezes. A razão contra a fome, tão relatada pela imprensa, não foi mencionada como motivo principal, nenhuma vez.

Gráfico Nº 1: Classificação das razões principais para comer o Tè

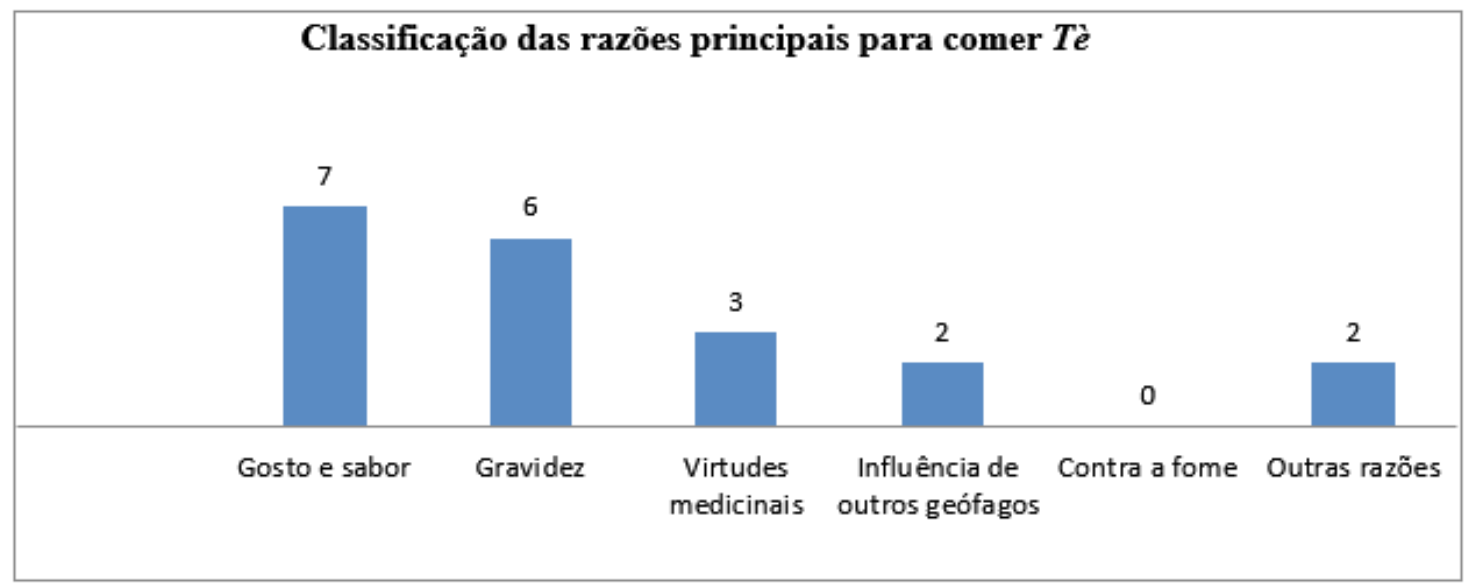

Fonte: Entrevistas.

Conforme a segunda análise, obtivemos uma hierarquia de razões no conjunto das entrevistas, considerando a ordem que foram apresentadas. Essa análise é um indicador minimamente objetivo para afirmarmos que os haitianos consultados comem tè especialmente por conta de gosto e sabor (7 importantíssima e 6 muito importante) e de gravidez (6 importantíssima e 5 importante). E que também comem tè por conta de virtudes medicinais ( 5 importante e 4 menos importante) e influência de outros geófagos ( 5 importante e 3 menos importante). Mas que não comem tè motivados pela fome; contra a forme figura raramente e, ainda assim, uma vez como importante ou uma como menos importante.

Gráfico $\mathbf{N}^{\circ}$ 2: Classificação das razões relatadas para comer Tè

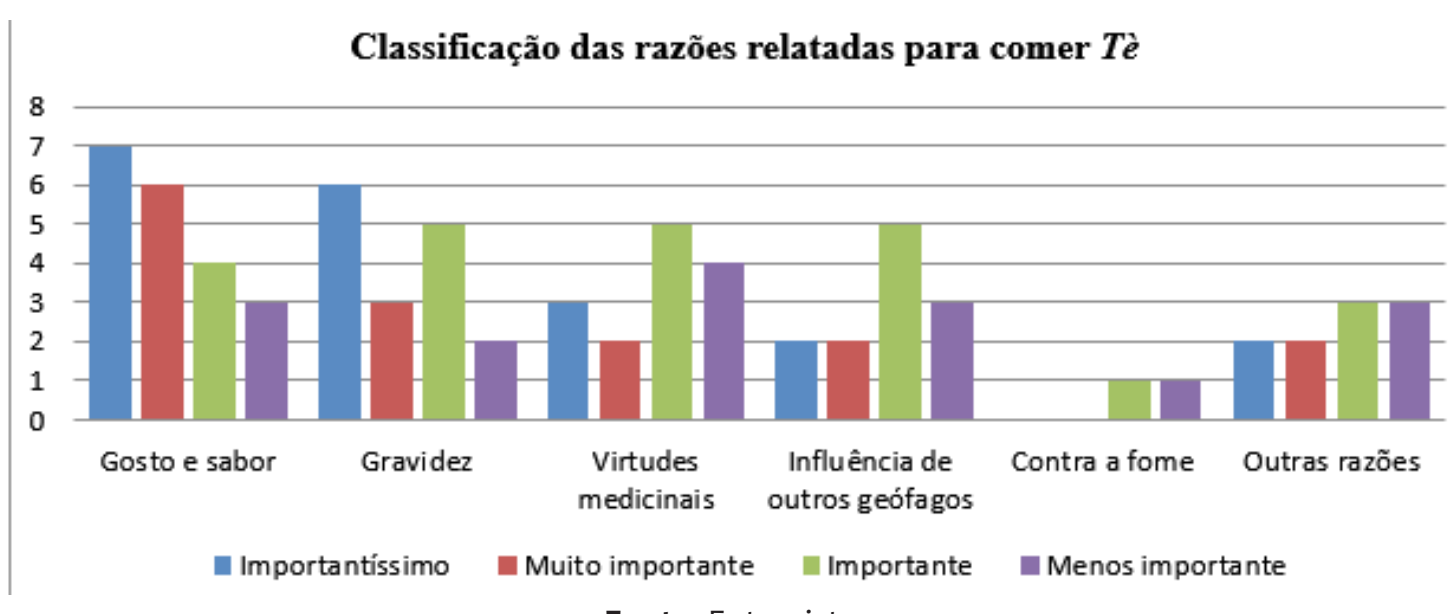

Fonte: Entrevistas.

Evidentemente, nenhum dos homens relatou gravidez como razão. No entanto, alguns explicaram que essa é uma das principais razões para 
a prática entre as mulheres. Eles relataram fatos relacionados às mulheres grávidas - acompanhante, mãe, irmã ou vizinha - comendo o tè para corroborarem suas explicações. Finalmente, contra a fome apareceu duas vezes no conjunto. Isso quer dizer que corrobora muito mais sua insignificância do que qualquer outra coisa.

Apresentamos, abaixo, extratos de discursos dos entrevistados que explicam o motivo de comer o tè. Caroline ${ }^{1}$, mulher de 24 anos, explicou que consome tè por várias razões, nenhum relacionada à fome.

Eu gosto especialmente do tè por seu sabor e cheiro. Mas eu como também porque reduz a minha dor abdominal durante o meu período de menstruarão. Esta prática existe desde a minha infância, apesar da pressão exercida sobre mim por meus pais. Minha mãe me obrigou a não comer, enquanto ela comia todos os dias, especialmente quando ela estava grávida de meu irmão mais novo. Hoje, ela me aceitou como eu sou porque ela acredita que se eu como, ela é responsável.

Jean, homem de 34 anos, por sua vez, apresentou com certeza e clareza as razões para comer tè. No entanto, insistiu que é geófago por causa do sabor do tè. Ele explicou que tem esse comportamento devido à influência de sua esposa que é geófaga.

O tè tem um sabor especial, é claro. Mas, neste papel de geófago, eu fui influenciado pela minha esposa. Eu também sou um fumante pela influência de meu pai. Então, eu comi o tè por imitação, apesar do fato de que é, acima de tudo, delicioso. Aparentemente, também é perigoso quando as pessoas não consomem com moderação.

Com as entrevistas, também estávamos interessados em rastrear a origem da prática e a frequência de uso de tè, para cada entrevistado. $\mathrm{Na}$ maioria dos casos, a prática remonta à infância. Em outros, é uma prática típica de alguns momentos. Por exemplo, as mulheres consomem um pouco mais quando estão grávidas. "Isso evita cuspir", explicam. Neste caso, explicam que o tè tem virtudes medicinais. Na gravidez, o tè reduz o risco de vômito, acreditam. Algumas também comem quando estão no período de

1 Caroline e outros nomes não são os nomes reais dos entrevistados. Usamos nomes fictícios para cumprir um acordo de discrição em relação ao nome dos entrevistados, condição para obtermos as entrevistas. 
menstruação, pois acreditam e relatam que o consumo do tè reduz a dor abdominal.

No que concerne ao consumo do tè em relação à fome, Caroline contou que, no caso dela, não importa. Não nega que o tè pode saciar a fome, também. Mas, neste caso, disse que preferia comprar outra coisa para satisfazer melhor sua fome, por exemplo, pão. Explicou que o tè é algo comprado e é menor em volume ou massa e mais caro em preço do que o pão. Por conta de fome, ninguém faz doações de tè à outra pessoa. Enquanto se faz doações de pão, algumas vezes. O tè tem um preço e as pessoas comem por gosto, não para compensar a falta de outros alimentos. Outro entrevistado, Jean, também teceu comentários na mesma direção, especificando que, se fosse buscar uma solução para a fome, teria escolhido outra comida.

Para Johanne, mulher de 27 anos, não há como pensar em resolver o problema da fome com o tè, pois é algo que é consumido em quantidades pequenas. Não é uma substância de grande valor nutricional. O uso do tè para resolver o problema da fome pode implicar em morte. Ela também critica o fato de que tè, às vezes, é preparado em condições insalubres. Neste sentido, prefere preparar o tè em sua casa para reduzir o risco de contaminação por bactérias ou outros patógenos.

Para Anne, mulher de 30 anos, tè não pode saciar a fome. As pessoas podem comer apenas quando desejarem. Para corroborar suas ideias, se refere a sua mãe e a sua tia que emigraram para os Estados Unidos, há cinco anos. Ambas são muito amantes do tè.

O tè não é para combater a fome. Nós comemos tè porque temos o desejo. Além disso, torna-se delicioso quando é misturado com manteiga e sal. Minha mãe e minha tia moram nos Estados Unidos da América, há cinco anos. Todos os anos eu envio para elas uma quantidade suficiente de tè, embalado. Onde elas estão, não têm nenhum problema de fome. Comer tè é uma escolha pessoal.

O fato relatado por Anne, a exportação de tè para os Estados Unidos, também é encontrado em outras sociedades onde há imigrantes que são geófagos. Pessoa observou a prática da geofagia entre mulheres africanas em Paris. Essas mulheres imigrantes importam uma argila da África para vender nos mercados e para uso próprio; o kaolin. Neste caso, a comunidade de imigrantes africanas usa o kaolin como uma das especiarias utilizadas para 
preparar alimentos (PESSOA, 2005).

Em conclusão, podemos notar que as razões apresentadas pelo geófagos são diferentes das apresentadas pela imprensa brasileira; negam a conexão entre geofagia e fome descrita pelo senso comum jornalístico brasileiro. Enquanto a imprensa menciona que os haitianos comem tè para não sucumbirem à fome, as entrevistas revelaram dimensões nada utilitárias deste hábito; gosto, sabor, crenças em suas virtudes medicinais, especialmente as relacionadas à gestação, além de relatarem um costume que passa de geração para geração. Em outras palavras, as razões estão relacionadas às tradições e aos costumes culturais. $O$ uso do tè como alimento não é explicado ou não é uma resposta dos haitianos às necessidades orgânicas como a fome.

\section{CONSIDERAÇÕES}

A geofagia é um conceito que designa a prática humana de ingerir terra. Essa prática existe em diversas culturas, sob diferentes formas. O tè é uma forma da geofagia haitiana. A fabricação e o consumo do tè foram abordados e difundidos inapropriadamente pela imprensa internacional e, particularmente, a brasileira; foi chamado de "biscoito de barro" utilizado para matar a fome.

Revisamos escritos da imprensa brasileira em torno de dois períodos 2008 e 2010 - e procuramos demonstrar que, em alguma medida, ela criou e utilizou o termo "biscoito de barro" ou "bolacha de barro" e, assim, interpretou mal a geofagia haitiana; de modo equivocado e sensacionalista. $\mathrm{O}$ termo foi criado e usado pela imprensa internacional - inclusive a brasileira - que estava no Haiti durante os motins da fome de 2008 e o terremoto de 2010.

Analisando um conjunto de entrevistas com geófagos - a geofagia haitiana narrada por geófagos haitianos - pudemos revelar, por contraposição, que a imprensa não observou o consumo do tè como uma prática cultural, nem mesmo teve sensibilidade para observar o tè em um contexto sociocultural. As entrevistas revelaram que os comedores de tè apreciam seu gosto, suas virtudes medicinais e aprendem este hábito alimentar do mesmo modo que tantos outros que passam de geração para geração.

\section{AGRADECIMENTOS}


Agradecemos ao Programa de Alianças para Educação e a Capacitação da Organização dos Estados Americanos e o Grupo Coimbra de Universidades Brasileiras- PAEC OEA/GCUB e a Coordenação de Aperfeiçoamento de Pessoal de Nível Superior - CAPES/MEC. 
CADERNOS DE COMUNICAÇÃO

UNIVERSIDADE FEDERAL DE SANTA MARIA

\section{REFERÊNCIAS}

AGÊNCIA BRASIL. Haitianos vão receber 54 toneladas de alimentos doados por brasileiros. Globo.com. Rio de Janeiro, 13 fev. 2017. Disponível em: http://revistagloborural. globo.com/Noticias/Agricultura/noticia/2017/02/haitianos-vao-receber-54-toneladas-de-alimentos-doados-por-brasileiros.html. Acesso em: 2 ago. 2017.

AGÊNCIA DE NOTÍCIAS DE PORTUGAL. Crianças comem bolos de barro para matar a fome. RTP Notícias, Lisboa, 29 jan. 2010. Disponível em: https://www.rtp.pt/noticias/ mundo/criancas-comem-bolos-de-barro-para-matar-a-fome_n314776. Acesso em: 24 ago. 2018.

ALTERPRESSE. Haïti/Émeutes de la faim: le Programme alimentaire mondial lance un appel d'urgence. Alterpresse, Porto Príncipe, 08 abr. 2008. Disponível em: http://www. alterpresse.org/spip.php?article7108\#.WIVZoa7iblU. Acesso em: 24 dez. 2017.

ASSOCIATED PRESS. Haiti's poor resort to eating mud as prices rise. NBCnew.com. Nova lorque, 29 jan. 2008. Disponível em: http://www.nbcnews.com/id/22902512/ns/world news-americas/t/haitis-poor-resort-eating-mud-prices-rise/\#.W4CnPc5KjIU. Acesso em: 24 ago. 2018.

BERGAMO, M. Fome. Folha de São Paulo, São Paulo, 03 mar. 2008. Disponível em: http:// www1.folha.uol.com.br/fsp/ilustrad/fq0303200806.htm. Acesso em: 14 ago. 2017.

BOURDIEU, P. Sobre a televisão. Rio de Janeiro: Zahar, 1997.

BRACCIANO, W.; CLAUDET, S. Haïti: les émeutes de la faim. France24, 23 mai. 2008. Disponível em: http://www.france24.com/fr/20080523-ha-ti-meutes-faim-haiti. Acesso em: 9 jan. 18.

CARROLL, R. HAITI: Mud cakes become staple diet as cost of food soars beyond a family's reach. The Guardian, 28 jul. 2008. Disponível em: https://www.theguardian.com/ world/2008/jul/29/food.internationalaidanddevelopment. Acesso em: 15 jul. 2017.

CÁSSIO, R. Biscoito da terra. Globo.Com. Campinas, 09 mai. 2014. Disponível em: http:// g1.globo.com/sp/campinas-regiao/haiti-bracos-da-paz/platb/2014/05/09/biscoitos-da-terra/. Acesso em: 24 ago. 2018.

CHAMPAGNE, P. A visão midiática. In: BOURDIEU, P. A miséria do mundo. Petrópolis, RJ: Vozes, 1998.

CHAMPAGNE, P. La double dependance. Quelques remarques sur les rapports entre les champs politique, économique et journalistique. Hermès, Paris, v. 17-18, 1995 p. 215-229.

CHAPART, A. Les géophages. Paris: P. Réaux, 1926.

COLLINGON, R. À propos des troubles des conduites alimentaires; du pica des médecins à la géophagie des géographes, des voyageurs et des ethnologues. Psychopathologie africaine, Dakar, v. 24, n. 3, 1992, p. 385-396.

DIÁRIO DE PERNAMBUCO. Violência, muito lixo e biscoitos de barro. Diário de Pernambuco, Recife, 09 set. 2009. Disponível em: http://www.impresso.diariodepernambuco. com.br/app/noticia/cadernos/mundo/2017/09/og/interna_mundo,175345/violencia-muito-lixo-e-biscoitos-de-barro.shtml. Acesso: 9 de jan. 2018. 
ETWAREEA, R. Haïti. Des galettes de boue pour tout repas. Courrier International, Lausanne, 01 fev. 2008. Disponível em: http://www.courrierinternational.com/article/2008/02/01/des-galettes-de-boue-pour-tout-repas. Acesso em: 17 abr. 2017.

GARBIN, L. Diário do Haiti: Bolacha de barro ajuda na economia haitiana. Estado de São Paulo, São Paulo, 02 set. 2017 Disponível em: http://internacional.estadao.com.br/blogs/ radar-global/diario-do-haiti-bolacha-de-barro-ajuda-na-economia-haitiana/. Acesso em: 9 de jan. 2018.

HUNTER, J.; KLEINE, R. Geophagy in Central America. The Geographical Review. v. 74, 1984, p. 157-169.

INSTITUT HAÏTIEN DE STATISTIQUE ET D'INFORMATIQUE. Population totale, population de dix-huit ans et plus. Ménages et densités estimés en 2015. Port-au-Prince: IHSI. 2015. JANIN, P. Les “émeutes de la faim”: une lecture (géo-politique) du changement (social). Politique étrangère, 2009/2, p. 251-263.

KACHANI, A. T; CORDAS, T. A. Da ópera-bufa ao caos nosológico: pica. Revista Psiquiátrica Clínica. v. 36, 2009, p. 162-169.

LACEY, M. Do "New York Times", em Porto Príncipe, Haiti. Folha de São Paulo, São Paulo, 21 abr. 2008. Disponível em: http://www1.folha.uol.com.br/fsp/dinheiro/fi2104200814. htm. Acesso em: 14 ago. 2017.

LAREZO, M. Frei de Jaci instala padaria para crianças que comiam barro no Haiti. Globo. Com. Rio Preto e Araçatuba, 17 ago. 2013. Disponível em: http://g1.globo.com/sao-paulo/ sao-jose-do-rio-preto-aracatuba/noticia/2013/08/frei-de-jaci-instala-padaria-para-criancas-que-comiam-barro-no-haiti.html. Acesso em: 24 ago. 2018.

LE FIGARO. Haïti: censure contre Alexis. Le figaro.fr, Paris, 12 abr. 2008. Disponível em: http://www.lefigaro.fr/flash-actu/2008/04/12/01011-20080412FILWWW00583-haiti-lesenat-vote-la-censure-contre-alexis.php. Acesso em: 29 de dez. 2017.

LIEWIG, N.; RAUTUREAU, M.; GOMES, C. Les argiles et la santé humaine d'hier à aujourd'hui. Étude et gestion des sols. Orléans, v. XIX, 2012.

LIMA, G. No Haiti, biscoito de barro ‘engana’ a fome. Blog do Gilberto Lima, 26 jul. 2009. Disponível em: http://gilbertolimajornalista.blogspot.com.br/2009/07/na-haiti-biscoito-de-barro-engana-fome.html. Acesso em: 2 jun. 2017.

OLIVEIRA, M. I. Motins da fome na França e na Inglaterra no século XVIII. Revista Temas \& Matizes. Cascável, v. 4, n. 8, 2005, p. 81-91.

PESSOA, G. Le goût de l'argile. La géophagie des femmes africaines dans le quartier de Château Rouge (enquête). Terrains \& travaux, Paris, v. 9, 2005/2, p. 177-191.

PORTO, H. Cenário no Haiti já era de tragédia antes do terremoto, diz MV Bill. Globo.com, Rio de Janeiro, 14 jan 2010. Disponível em: http://g1.globo.com/Noticias/Mundo/o,,MUL1447382-5602,00-CENARIO+NO+HAITI+JA+ERA+DE+TRAGEDIA+ANTES+DO+TERREMOTO+DIZ+MV+BILL.html. Acesso em: 23 jul. 2017.

SEDEL, J. Les médias et la banlieue. Paris: Le Bord de Le Eau, 2013.

TERRA. Contra fome, torta de lama vira alimento no Haiti. Terra. 03 ago. 2008. Disponí- 
vel em: http://noticias.terra.com.br/mundo/noticias/o,,Ol3041636-El8140,00-Contra+fome+torta+de+lama+vira+alimento+no+Haiti.html. Acesso em: 24 ago. 2018.

THOMAZ, O. R. O terremoto no Haiti, o mundo dos brancos e o Lougawou. Novos Estudos CEBRAP, n. 86, 2010, p. 23-39.

THOMPSON, E. P. Senhores e caçadores: origem da lei negra. Rio de Janeiro: Paz e Terra, 1987.

TISATTO, C. A fome e a educação no Haiti: uma ausência de direitos? Revista Acadêmica Licencia\&acturas. v. 4, n. 1, 2016, p. 52-59.

VIVAR, R. Lo de Haití es desolador; los niños hacen galletas de barro para poder comer algo. Eldiario.es. Cantabria, 30 jan. 2016. Disponível em: https://www.eldiario.es/norte/ cantabria/cantabria/situacion-Haiti-desoladora-galletas-comer_0_478752241.html. Acesso em: 24 ago. 2018. 


\section{Jhon Kelly Monacé}

Formado em sociologia pela Université d'État d'Haïti e fez mestrado em História pela mesma universidade. Atualmente, é doutorando em Desenvolvimento Regional da Universidade Federal do Tocantins - Planejamento Urbano e Regional/Demografia.

E-mail: jhon-kelly.monace@mail.uft.edu.br

\section{Temis Gomes Parente}

Professora Associada IV da UFT; Professora do Programa de Posgraduação em Desenvolvimento Regional da Univerisdade Federal do Tocantins.

E-mail:temis@uft.edu.br

\section{Antonio José Pedroso Neto}

Sociólogo. Bolsista de Produtividade em Pesquisa do CNPq. Pós-Doutorado pela FACE/CEDEPLAR/UFMG. Doutor em Ciências Sociais (UFSCar). Estágio Sanduíche (EHESS/Paris). Professor Associado I da Universidade Federal do Tocantins (UFT). Pesquisador do Programa de Pós-Graduação em Comunicação e Sociedade (PPGCOM) e do Programa de Pós-Graduação em Desenvolvimento Regional (PPGDR), ambos da UFT.

E-mail: ajpedrosoneto@uol.com.br 